\title{
High plasma levels of high mobility group box 1 is associated with the risk of sepsis in severe blunt chest trauma patients: a prospective cohort study
}

\author{
Xiao-Wen Wang ${ }^{1}$, Avash Karki ${ }^{2}$, Xing-Ji Zhao ${ }^{3}$, Xiao-Yong Xiang ${ }^{2}$ and Zhi-Qian Lu ${ }^{1 *}$
}

\begin{abstract}
Background: High mobility group box 1 (HMGB1) is a late mediator of systemic inflammation. Extracellular HMGB1 play a central pathogenic role in critical illness. The purpose of the study was to investigate the association between plasma HMGB1 concentrations and the risk of poor outcomes in patients with severe blunt chest trauma.

Methods: The plasma concentrations of HMGB1 in patients with severe blunt chest trauma (AIS $\geq 3$ ) were measured by a quantitative enzyme-linked immunosorbent assay at four time points during seven days after admission, and the dynamic release patterns were monitored. The biomarker levels were compared between patients with sepsis and non-sepsis, and between patients with multiple organ dysfunction syndrome (MODS) and non-MODS. The related factors of prognosis were analyzed by using multivariate logistic regression analysis. The short-form 36 was used to evaluate the quality of life of patients at 12 months after injury.

Results: Plasma HMGB1 levels were significantly higher both in sepsis and MODS group on post-trauma day 3, 5, and 7 compared with the non-sepsis and non-MODS groups, respectively. Multivariate analysis showed that HMGB1 levels and ISS were independent risk factors for sepsis and MODS in patients with severe blunt chest trauma.

Conclusions: Plasma HMGB1 levels were significantly elevated in patients with severe blunt chest trauma. HMGB1 levels were associated with the risk of poor outcome in patients with severe blunt chest trauma. Daily HMGB1 levels measurements is a potential useful tool in the early identification of post-trauma complications. Further studies are needed to determine whether HMGB1 intervention could prevent the development of sepsis and MODS in patients with severe blunt chest trauma.
\end{abstract}

Keywords: Chest trauma, High-mobility group box 1, Inflammation, Sepsis, MODS, Complications

\section{Background}

Trauma is a major cause of mortality and morbidity in young adults and children in mainland China [1]. Chest trauma is a common reason for patients to be admitted to emergency department as a result of serious traffic accidents. Accurate identification of severe chest trauma patients who have the potential to deteriorate rapidly and are at risk of developing of post-trauma complications has

\footnotetext{
*Correspondence: Izqsurgery@163.com

'Department of Cardiothoracic Surgery, Shanghai Jiao Tong University Affiliated Sixth People's Hospital, NO. 600 Yishan Road, Shanghai 200233, PR China

Full list of author information is available at the end of the article
}

also been difficult. Furthermore, diagnosis of sepsis can be troublesome in severe traumatic patients as positive bacteriologic specimens may be late or absent, the clinical interpretation of local colonization may be ambiguous, and traditional infection markers such as core body temperature and white blood cell counts may show nonspecific alterations [2].

A number of inflammatory cytokines, such as interleukin (IL)-1, IL-6, and IL-8, tumor necrotizing factor $(\mathrm{TNF}-\alpha)$, which are involved in systemic inflammation caused by trauma, infection, cancer, chronic disease, and surgery [3], have been assessed for their roles as potential markers of the severity of inflammatory response. 
High mobility group box protein 1 (HMGB1) discovered originally as a nonhistone nuclear deoxyribonucleic acids binding protein has been identified as an important late mediator of systemic inflammation in contrast to other inflammatory cytokines mentioned. It has been demonstrated that HMGB1 plays a key pathogenic role in the pathogenesis of sepsis and multiple organ dysfunction syndrome (MODS) in critical illness including major trauma [4-8]. Therefore, HMGB1 is an interesting candidate marker for monitoring patients with severe chest blunt trauma.

However, we are lacking knowledge about the changes in HMGB1 levels during the course of severe blunt chest trauma or its relationship with the extent of trauma and the prognosis of those patients. The aim of the study was to investigate the time course of HMGB1 levels in patients with blunt chest trauma and to determine whether the levels of HMGB1 were associated with the risk of sepsis and MODS after severe blunt chest trauma.

\section{Methods}

We undertook a prospective cohort study in between April 2011 and January 2012. All consecutive eligible patients were admitted to our surgical ICU and a detailed questionnaire assessing the medical history and physical state of the patients were filled out by an experienced physician. The study was strictly observational and did not interfere the decision-making process and clinical management. Patients were treated according to the standard management without having any reference to the response tends of HMGB1 in their clinical evaluation. The protocol for this study was approved by the Ethical and Protocol Review Committee of the Chongqing Medical University, Chongqing, China, and informed consent was obtained from all patients or their next of kin. Patient confidentiality was preserved according to the guidelines for the studies of human subjects. All of the participants were Han Chinese.

\section{Inclusion and exclusion criteria}

Criteria for inclusion in the study were age $\geq 16$, blunt chest trauma with a severe thoracic trauma $\left(\right.$ AIS $\left._{\text {chest }}\right) \geq$ 3 , primary admission to the hospital within $24 \mathrm{~h}$ after injury (time of injury is defined as the time of pre-hospital emergency medical service activation), and survival following the trauma of more than seven days. Multiple trauma patients meeting the criteria were also admitted. Exclusion criteria were penetrating trauma, steroidal and non-steroidal anti-inflammatory medication therapy.

\section{Clinical evaluation and definitions}

Multiple rib fracture was defined as breakage of 3 or more ribs, and flail chest was a traumatic condition in which there are three or more contiguous ribs with fractures in two or more places [9]. Sepsis was diagnosed when patients met all of the following criteria: clinical evidence of infection, body temperature above $38.5^{\circ} \mathrm{C}$ or below $36.5^{\circ} \mathrm{C}$, and leukocyte count greater than $10 \times 10^{9}$ / 1 or less than $4 \times 10^{9} / \mathrm{l}$. MODS is usually defined as a Marshall score of 4 or more for at least 2 consecutive days [10]. Stricter definition of MODS as a Marshall score of 6 or more was used in this study. Scores for MODS were calculated as the sum of the simultaneously obtained individual organ scores during the first week of ICU stay [11]. The bloodstream infections were diagnosed according to the isolation of a predominant organism from blood cultures obtained under sterile conditions.

\section{Clinical data collection}

Data, including demographic characteristics, medical histories, mechanism of injury, injury diagnoses, injury severity score (ISS), chest abbreviated injury score $\left(\mathrm{AIS}_{\text {chest }}\right)$, management, and clinical course, were collected by a structured patient interview. Determination of ISS and AIS were performed by independent evaluators according to the Abbreviated Injury Scale 2005 [12]. The traumatic patients were stratified into two groups according to ISS: higher injury severity scores (ISS 20 or more) group and lower injury severity scores (ISS 20 or less) group. Alternatively, patients were divided into sepsis group and non-sepsis group according to development of sepsis, or MODS group and non-MODS group based on the MODS score. The quality of life health survey (using the Chinese version of Short Form [SF 36]) was taken 12 months after injury.

\section{Blood sample collection}

Venous peripheral blood was drawn from patients on post-trauma days $1,3,5$ and 7. Samples were collected in potassium ethylenediamine tetra-acetic acid (EDTA) coated bottles, and were centrifuged at 5,000 g for $5 \mathrm{mi}-$ nutes to remove the cellular components. The plasma obtained was stored at $-80^{\circ} \mathrm{C}$ for longer term storage.

\section{Samples assay}

The plasma samples were tested for HMGB1 levels by enzyme-linked immunosorbent assay (ELISA), using a commercially available human HMGB1 ELISA kit (USCN Life Sciences, Wuhan, Hubei, China), and according to the manufacturer's instruction. The minimum detectable level of HMGB1 was $12 \mathrm{pg} / \mathrm{ml}$. The dilution curve of the plasma samples was parallel to the standard dilution curve.

\section{Statistical analysis}

Differences between groups were evaluated by Student $t$ test for continuous variables and by $\chi^{2}$ test or Fisher exact for categorical variables. Logistic regressions were used as 
odds ratios (ORs) with 95\% CI adjusting for HMGB1 levels, ISS, pneumo/hemomediastinum, and tracheotomy. All statistical tests were two sided, and $P$ value $<0.05$ was considered statistically significant. Statistical analyses were performed using SPSS 16.0 (SPSS, Chicago, Illinois, USA).

\section{Results}

Study sample and injury-related characteristics

In the study, a total of 57 patients with blunt chest trauma were recruited and the mean age was $44.4 \pm 12.6$. 41 patients $(71.9 \%)$ were male and $16(28.1 \%)$ were female. The mean ISS was $17.4 \pm 6.1$ and the mean AIS chest was $3.5 \pm 0.5$. The main patients' demography and clinical data were presented in Table 1 . Of the patients who were initially evaluated, 26 patients were excluded from the study due to the following reasons: admission later than 24 hours after trauma $(n=5)$, died within 7 days $(n=3)$, age younger than 16 years $(n=4)$, penetrating trauma $(n=5)$, and did not have post-trauma blood sample available $(\mathrm{n}=9)$.

Out of the 57 trauma cases, 35 patients $(61.4 \%)$ were due to motor vehicle crashers, $17(29.8 \%)$ were caused by falling and $5(8.8 \%)$ were by other trauma. 13 patients had blunt chest trauma only and 44 had multiple injuries. Multiple rib fractures were present in 54 patients (94.7\%) and 9 of them (15.8\%) had flail chest. Pleural alterations were observed in $52(91.2 \%)$ cases, in which 35 were of pneumothorax (61.4\%), 51 of hemothorax (89.5\%), and 25 of hemopneumothorax (43.9\%). Pulmonary contusion was evident radiographically in 50 (87.8\%), and among them, there were 24 cases of bilateral pulmonary contusion (42.1\%).

Overall, 14 patients $(24.5 \%)$ developed sepsis, 5 patients (8.8\%) MODS, and two of these patients died. $47(82.5 \%)$ patients in total required tube thoracostomy, $12(21.2 \%)$ were treated surgically by thoracotomy as illustrated in Table 1, and tracheotomy rate was $15.8 \%$ $(n=9)$. The length of intensive care unit (ICU) and hospital stay were $11.5 \pm 8.6$ day and $57.6 \pm 28.8$ days, respectively. Long-term follow-up was complete for 52 patients (91.2\%). Mean follow-up time was $16.7 \pm 4.1$ months.

\section{Changes in HMGB1 levels after trauma}

Figure 1 shows the plasma levels of HMGB1 at various time points. The mean plasma HMGB1 levels in blunt chest trauma patients on post-trauma day 1 were $43.8 \pm$ $13.1 \mathrm{ng} / \mathrm{ml}$, day $3(65.7 \pm 27.6 \mathrm{ng} / \mathrm{ml})$, day $5(72.5 \pm$ $29.8 \mathrm{ng} / \mathrm{ml})$, day $7(74.4 \pm 28.3 \mathrm{ng} / \mathrm{ml})$. The overall patterns of plasma concentration of HMGB1 were increased in patients on day 1 , peaked on day 5 and remained elevated through the consecutive 7 days.

Table 1 summarized the clinical characteristics of the two groups. The group with ISS $\geq 20$ had a higher proportion of patients with pneumothorax ( $85.7 \%$ vs. $47.2 \%$,
$P=0.004)$, bilateral pulmonary contusion $(61.9 \%$ vs. $30.6 \%$, $P=0.021)$, thoracotomy $(38.1 \%$ vs. $11.1 \%, P=0.016)$, and tracheotomy ( 38.1 vs. $2.8 \%, P<0.001)$. In a 12 months follow-up, patients in the group with ISS $<20$ group had significantly better physical component summary of SF 36 (71.3 \pm 5.5 vs. $64.7 \pm 7.0, P=0.001$ ).

As shown in Figure 2, the HMGB1 levels were significantly higher in high ISS group than those with lower ISS during day 3 to 7 . In patients with an ISS $\geq 20$, there were no statistically significant difference in mean HMGB1 levels on day $1(45.3 \pm 10.7 \mathrm{ng} / \mathrm{ml}$ vs $42.5 \pm$ $15.1 \mathrm{ng} / \mathrm{ml}, P=0.41$ ), whereas there were statistically significant increase in mean HMGB1 levels on days 3, 5, and 7 compared with those with ISS 20 or less (Day 3: $74.3 \pm 29.8 \mathrm{ng} / \mathrm{ml}$ vs $57.4 \pm 22.9 \mathrm{ng} / \mathrm{ml}, P=0.02$; Day 5 : $82.1 \pm 29.6 \mathrm{ng} / \mathrm{ml}$ vs $63.4 \pm 27.6 \mathrm{ng} / \mathrm{ml}, p=0.018$; Day 7 : $84.9 \pm 31.4 \mathrm{ng} / \mathrm{ml}$ vs $64.3 \pm 27.6 \mathrm{ng} / \mathrm{ml}, P=0.011)$.

\section{Plasma levels of HMBG1 related with sepsis and MODS}

A higher proportion of patients in the sepsis and MODS groups had flail chest $(50 \%$ vs. $4.7 \%, P<0.001 ; 60 \%$ vs. $13.5 \%, P=0.033)$, mechanical ventilation $(64.3 \%$ vs. $4.7 \%$, $P<0.001 ; 60 \%$ vs. $15.4 \%, P=0.045)$, thoracotomy $(64.3 \%$ vs. $7.0 \%, P<0.001 ; 60.0 \%$ vs. $17.3 \%, P=0.045)$, tracheotomy $(42.9 \%$ vs. $7.0, P=0.001 ; 60 \%$ vs. $11.5 \% ; P=0.025)$ compared with non-sepsis and non-MODS groups, respectively. Moreover, more patients in the MODS group had pneumo/hemomediastinum $(60 \%$ vs. $7.7 \%, P=$ 0.011). The physical component summary of the SF 36 was significantly worse for patients in sepsis and MODS groups than for those in non-sepsis and non-MODS groups (all $\mathrm{P}<0.05$, Table 1 ).

Figure 3 showed that statistically significantly higher HMGB1 levels on post-trauma day 3, 5 and 7 were observed in patients who developed sepsis (all $P<0.001$ ), but the levels were not significantly different on day 1 between sepsis patient $(48.4 \pm 12.3 \mathrm{ng} / \mathrm{ml})$ and nonsepsis patient $(42.2 \pm 10.3 \mathrm{ng} / \mathrm{ml})(P=0.12)$. In contrast, patients in MODS group had significantly higher HMGB1 levels when compared with those of non MODS group on the first day $(53.2 \pm 9.3 \mathrm{ng} / \mathrm{ml}$ vs $42.7 \pm 13.1 \mathrm{ng} / \mathrm{ml}[P=$ $0.042])$, the third day $(97.3 \pm 23.1 \mathrm{ng} / \mathrm{ml}$ vs $62.0 \pm 25.8 \mathrm{ng} /$ $\mathrm{ml}[P=0.001])$, the fifth day $(117.4 \pm 13.7 \mathrm{ng} / \mathrm{ml}$ vs $67.3 \pm$ $26.6 \mathrm{ng} / \mathrm{ml}[P<0.001])$, the seventh day $(129.8 \pm 13.6 \mathrm{ng} /$ $\mathrm{ml}$ vs $67.9 \pm 25.3 \mathrm{ng} / \mathrm{ml}[P<0.001]$ ) (Figure 4 ).

\section{Multivariate analysis}

The association of plasma HMGB1 levels with the risk of sepsis and MODS was assessed after adjusting for potential confounding variables in multivariate analyses. The results showed that the HMGB1 level and ISS were independent risk factors for the development of sepsis [1.89 (95\% CI, 1.25 2.91; P = 0.003); 2.23 (95\% CI, $1.22 \sim$ 4.08; $\mathrm{P}=0.011)$ ] and MODS of chest trauma patients [1.78 
Table 1 Demographic and clinical characteristics of the patients

\begin{tabular}{|c|c|c|c|c|c|c|c|}
\hline Variable & Total & ISS $<20$ & ISS $\geq 20$ & Sepsis group & Non sepsis group & MODS group & Non MODS group \\
\hline \multicolumn{8}{|l|}{ Gender } \\
\hline Female & $16(28 \%)$ & $10(27.8 \%)$ & $6(28.6 \%)$ & $2(14.3 \%)$ & $14(32.6 \%)$ & $0(0)$ & $16(30.8 \%)$ \\
\hline Male & $41(72 \%)$ & $26(72.2 \%)$ & $15(71.4 \%)$ & $12(85.7 \%)$ & $29(76.4 \%)$ & $5(100 \%)$ & $36(69.2 \%)$ \\
\hline Age (years) & $44.4 \pm 12.6$ & $43.1 \pm 9.9$ & $46.8 \pm 16.2$ & $42.4 \pm 18.7$ & $45.1 \pm 10.1$ & $47.3 \pm 19.8$ & $42.1 \pm 13.4$ \\
\hline \multicolumn{8}{|l|}{ Mechanism of injury } \\
\hline Motor vehicle crasher & 35 (61\%) & $24(66.7 \%)$ & $11(52.4 \%)$ & $6(42.9 \%)$ & $29(67.4 \%)$ & $4(80.0 \%)$ & $31(59.6 \%)$ \\
\hline Falls & $17(30 \%)$ & $8(22.2 \%)$ & $9(42.9 \%)$ & $8(57.1 \%)$ & 9 (20.9\%) & $1(20.0 \%)$ & $16(30.8 \%)$ \\
\hline other & $5(9 \%)$ & $4(11.1 \%)$ & $1(4.8 \%)$ & $0(0 \%)$ & $5(11.6 \%)$ & $0(0)$ & $5(9.6 \%)$ \\
\hline AlS Chest & $3.5 \pm 0.5$ & $3.2 \pm 0.06$ & $3.9 \pm 0.08^{* *}$ & $3.71 \pm 0.47^{\#}$ & $3.35 \pm 0.53$ & $3.92 \pm 0.71$ & $3.29 \pm 0.42$ \\
\hline ISS & $17.4 \pm 6.1$ & $13.4 \pm 2.97$ & $24.2 \pm 3.8^{* *}$ & $22.0 \pm 5.0^{\# \#}$ & $15.8 \pm 5.8$ & $26.8 \pm 4.81 \& \&$ & $16.3 \pm 4.25$ \\
\hline Pneumo/Hemomediastinum & $7(12 \%)$ & $2(5.6 \%)$ & $5(23.8 \%)$ & $3(21.4 \%)$ & $4(9.3 \%)$ & $3(60 \%) \&$ & $4(7.7 \%)$ \\
\hline Head/Brain injury & $36(63 \%)$ & $21(58.3 \%)$ & $15(71.4 \%)$ & $10(71.4 \%)$ & $26(60.5 \%)$ & $3(60 \%)$ & $33(63.5 \%)$ \\
\hline Abdominal injury & $20(35 \%)$ & $12(33.3 \%)$ & $8(38.1 \%)$ & $4(28.6 \%)$ & $16(37.2 \%)$ & $3(60 \%)$ & $17(32.7 \%)$ \\
\hline Extremities/pelvis injury & $22(39 \%)$ & $11(30.6 \%)$ & $11(52.4 \%)$ & $5(35.7 \%)$ & $17(39.5 \%)$ & $1(20 \%)$ & $21(40.4 \%)$ \\
\hline Multiple rib fractures & $54(95 \%)$ & $34(94.4 \%)$ & $20(95.2 \%)$ & $14(100 \%)$ & $40(93.6 \%)$ & $5(100 \%)$ & $49(94.2 \%)$ \\
\hline Flail chest & $9(16 \%)$ & $3(8.3 \%)$ & $6(28.6 \%)$ & $7(50.0)^{\# \#}$ & $2(4.7 \%)$ & $3(60 \%) \&$ & $7(13.5 \%)$ \\
\hline Pneumothorax & $35(62 \%)$ & $17(47.2 \%)$ & $18(85.7 \%)^{*}$ & $11(78.6 \%)$ & $24(55.8 \%)$ & $5(100 \%)$ & $30(57.7 \%)$ \\
\hline Hemothorax & $51(90 \%)$ & $32(88.9 \%)$ & 19 (90.5\%) & $13(92.9 \%)$ & $38(88.4 \%)$ & $5(100 \%)$ & $46(88.5 \%)$ \\
\hline Hemopneumothorax & $25(44 \%)$ & $13(36.1 \%)$ & $12(57.1 \%)$ & $9(64.3 \%)$ & $16(37.2 \%)$ & $4(80.0 \%)$ & $21(40.4 \%)$ \\
\hline Pulmonary contusion & $50(88 \%)$ & $30(83.3 \%)$ & $20(95.2 \%)$ & $14(100 \%)$ & $36(83.7 \%)$ & $5(100 \%)$ & $45(86.5 \%)$ \\
\hline Bilateral pulmonary contusion & $24(42 \%)$ & $11(30.6 \%)$ & $13(61.9 \%)^{*}$ & $9(64.3 \%)$ & $15(34.9 \%)$ & $4(80.0 \%)$ & $20(38.5 \%)$ \\
\hline Tube thoracostomy & $47(83 \%)$ & $27(75.0 \%)$ & $20(95.2 \%)$ & $14(100 \%)$ & $33(76.7 \%)$ & $5(100 \%)$ & $42(80.8 \%)$ \\
\hline Mechanical ventilation & $11(19 \%)$ & $2(5.6 \%)$ & $9(42.9 \%)$ & $9(64.3 \%)^{\# \#}$ & $2(4.7 \%)$ & $3(60.0 \%) \&$ & $8(15.4 \%)$ \\
\hline Thoracotomy & $12(21 \%)$ & $4(11.1 \%)$ & $8(38.1 \%)^{*}$ & $9(64.3 \%)^{\# \#}$ & $3(7.0 \%)$ & $3(60.0 \%) \&$ & $9(17.3 \%)$ \\
\hline Tracheotomy & $9(16 \%)$ & $1(2.8 \%)$ & $8(38.1 \%)^{*}$ & $6(42.9 \%)^{\#}$ & $3(7.0 \%)$ & $3(60.0 \%) \&$ & $6(11 . \%)$ \\
\hline \multicolumn{8}{|l|}{ SF $36^{\mathrm{a}}$} \\
\hline PCS & $68.4 \pm 6.8$ & $71.3 \pm 5.5^{\S}$ & $64.7 \pm 7.0$ & $63.6 \pm 6.7^{\S}$ & $70.6 \pm 6.0$ & $59.3 \pm 7.1^{\S}$ & $69.8 \pm 8.2$ \\
\hline MCS & $76.3 \pm 8.4$ & $77.6 \pm 8.1$ & $74.4 \pm 8.7$ & $72.6 \pm 9.0$ & $77.5 \pm 7.9$ & $70.4 \pm 11.2$ & $77.1 \pm 10.1$ \\
\hline
\end{tabular}

Data are presented as mean \pm standard deviation or percentage (\%).

ISS: Injury Severity Score; VATS: Video-Assisted Thoracoscopic Surgery; PCS: Physical component summary; MCS: Mental component summary.

${ }^{a}$ Measures general aspects of health; scores range from 0 to 100 , with higher scores representing better well-being $\left({ }^{\S} \mathrm{P}<0.01\right)$.

Significant difference between ISS $<20$ group and ISS $\geq 20$ group $\left({ }^{*} \mathrm{P}<0.05 ;{ }^{* *} \mathrm{P}<0.01\right.$ ); Significant difference between Sepsis group versus Non-Sepsis group $\left({ }^{\#} \mathrm{P}<0.05 ;{ }^{\# \#} \mathrm{P}<0.01\right)$; Significant difference between MODS group versus Non-MODS group $(\& \mathrm{P}<0.05)$.

(95\% CI, $1.03 \sim 2.87 ; \mathrm{P}=0.017$ ); 2.07 (95\% CI, 1.44 3.95; $\mathrm{P}=0.035)$ ] (Table 2).

\section{Discussion}

The pathophysiologic stress of trauma would result in elevated HMGB1 production and that higher circulating levels of HNGB1 would be associated with the occurrence of poor outcome. This study showed markedly high plasma levels of HMGB1 in all patients with severe blunt chest trauma, and a significant association between higher plasma HMGB1 levels and the risk of sepsis and MODS after injury. Furthermore, higher levels of plasma HMGB1 were independently associated with a diagnosis of sepsis and MODS. The finding of strong correlation between with high HMGB1 levels and prognosis in patients with severe blunt chest trauma suggests that HMGB1, as an important late mediator of systemic inflammation, might play a role in the pathogenesis of sepsis and MODS.

Blunt injuries of chest wall are very common in clinical practice. Chest trauma is classified as blunt and penetrating injuries, and that $30 \%$ to $40 \%$ of the trauma patients required hospitalization [13]. Furthermore, chest injuries are directly responsible for $20 \%-25 \%$ of all trauma-related deaths $[14,15]$, which translates to approximately 25,000 deaths in the United States [13,16], and 150,000 in China each year. Blunt chest wall trauma does not involve any opening of the chest wall and can 


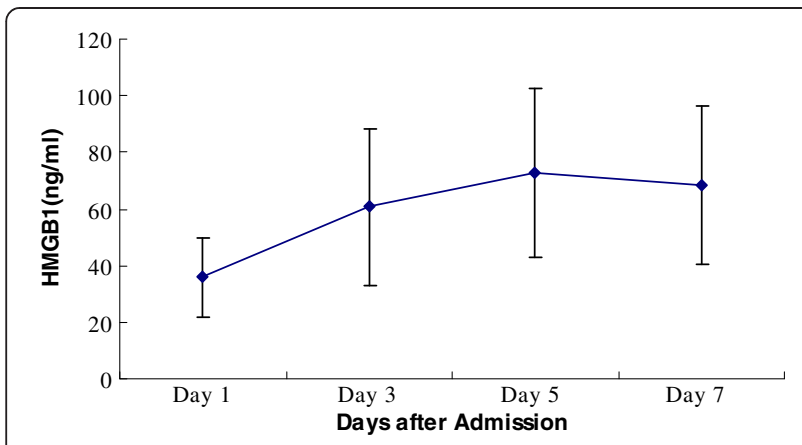

Figure 1 Time course of HMGB1 levels after trauma. Mean highmobility group box 1 levels were gradually increased during day 1-7 after trauma. HMGB1: high-mobility group box 1 .

vary in severity from minor bruising or an isolated rib fracture to severe crush injuries on both sides of the thorax, which can be lead to potentially fatal respiratory compromise [17]. Blunt forces applied to the chest wall cause trauma by three mechanisms: rapid deceleration, direct impact, and compression. The most common cause of blunt chest trauma is the motor vehicle accident, accounting for $70 \%-80 \%$ of blunt thoracic injuries [14]. This study showed that $61.4 \%$ of the trauma cases were caused by motor vehicle collisions. The rate is lower than previous research reports, probably due to a number of approaches employed in prevention motor vehicle accidents, like speed limit enforcement, passive restraints, and drunken driving legislation which have been increasingly effective in China.

Clinical and experimental data indicated that the existence of a severe inflammatory response on trauma that could lead to a secondary injury progressing within days. Blunt chest trauma induces systemic inflammatory response, and it is often associated with sepsis in the late phase of the trauma, which can lead to post-trauma complication contributing to poor outcome. The most deleterious element of the response and the best target

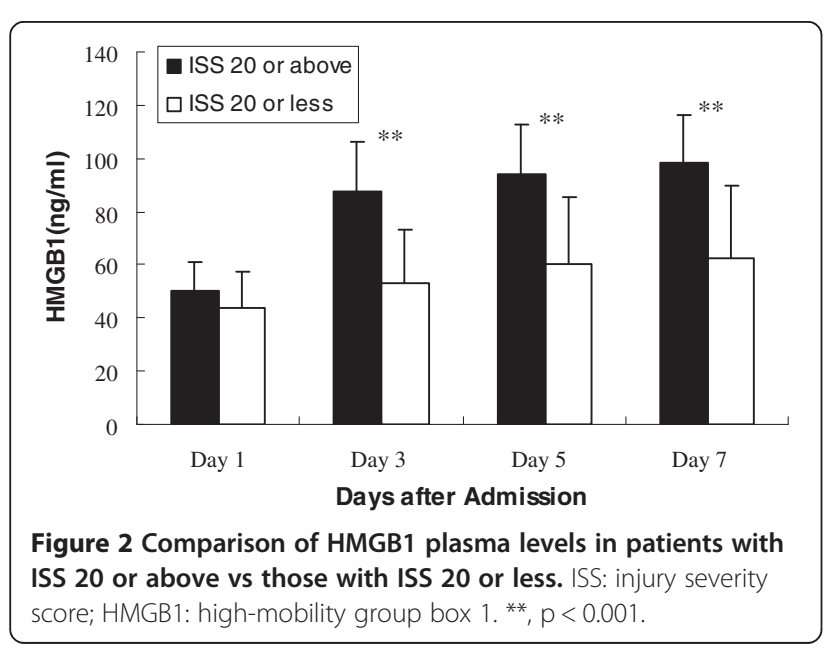

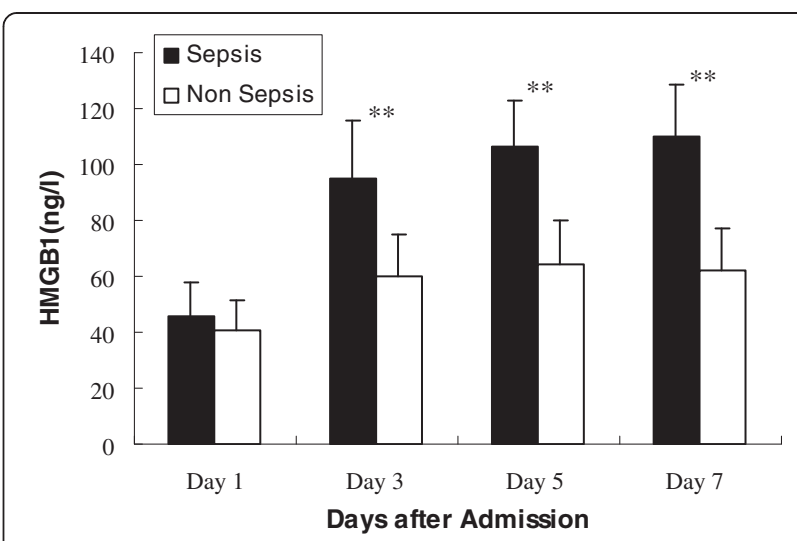

Figure 3 Comparison of HMGB1 plasma levels in patients with or without sepsis. HMGB1: high-mobility group box $1 .{ }^{* *}, p<0.001$.

for therapeutic intervention have not yet been identified. The question about the most suitable risk factors for the prognosis assessment of thoracic trauma remains. Moreover, there are a few studies examining the role of HMGB1 in the pathophysiological mechanisms of blunt chest trauma. This study has demonstrated that plasma HMGB1 levels were associated with the risk of post-trauma sepsis and MODS in blunt chest trauma patients.

HMGB1 has been demonstrated to play a central role in the initiation and propagation of the inflammatory response in traumatic injury. Wang et al. demonstrated that the persistent increase of plasma HMGB1 in septic patients is correlated with the degree of organ dysfunction and outcome [7]. Furthermore, Peltz et al. found that Plasma HMGB1 is significantly increased within $1 \mathrm{~h}$ of mechanical trauma in humans, and an increased HMGB1 level is associated with requiring longer duration of intensive care unit (ICU) stays in trauma patients [18]. The increased plasma HMGB1 contributes to the development of sepsis and MODS after trauma [19].

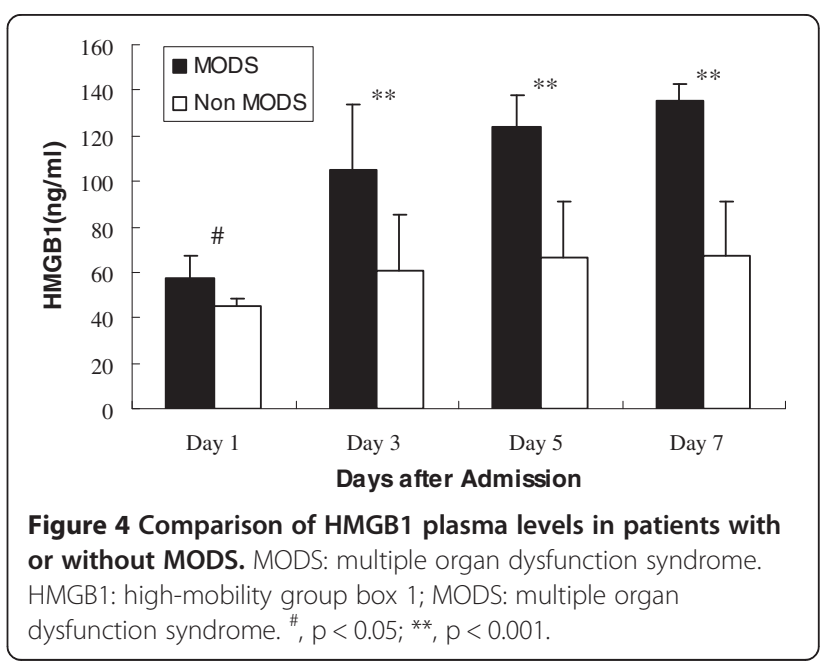


Table 2 Multiple logistic regression models of independent risk factors for sepsis and MODS of chest trauma patients

\begin{tabular}{lllll}
\hline Variable & $\begin{array}{l}\text { Sepsis } \\
\text { Odds ratio }(\mathbf{9 5 \%} \text { Cl) }\end{array}$ & $\begin{array}{l}\mathbf{P} \\
\text { value }\end{array}$ & $\begin{array}{l}\text { MODS } \\
\text { Odds ratio (95\% Cl) }\end{array}$ & $\begin{array}{l}\mathbf{P} \\
\text { value }\end{array}$ \\
\hline HMGB1 & $1.89(1.25 \sim 2.91)$ & 0.003 & $1.78(1.03 \sim 2.87)$ & 0.017 \\
ISS & $2.23(1.22 \sim 4.08)$ & 0.011 & $2.07(1.44 \sim 3.95)$ & 0.035 \\
Tracheotomy & $0.67(0.42 \sim 1.05)$ & 0.094 & - & - \\
Presence pneumo/hemomediastinum & - & - & $0.84(0.47 \sim 1.02)$ & 0.052 \\
\hline
\end{tabular}

HMGB1: High mobility group box 1; ISS: Injury Severity Score; MODS: multiple organ dysfunction syndrome.

Plasma HMGB1 remains increased for up to the 7 th days in patients with sepsis [5], and HMGB1 expression correlates with poor outcome in lung injury patients [20]. Our study, in agreement with previous reports, noted that a higher HMGB1 concentration was associated with the risk of developing sepsis and MODS in patients with chest trauma. Additionally, a great number of evidence has shown that burn injury induces an elevation in plasma HMGB1 concentration [21-23].

As shown in our study, the difference in plasma HMGB1 concentrations between blunt chest trauma patients with and without poor outcome (such as sepsis, and MODS) was significant. The plasma levels of HMGB1 in patients who developed sepsis remained at the same level throughout the course of the study. Plasma levels of HMGB1 in patients with MODS during the study increased from post-trauma day 1 to 7 . On the first day of trauma, there was no difference between the post-trauma infection and non-infection groups. However, from day 3 to day 7 , there was a statistically significant difference between the two groups. Plasma levels of HMGB1 from day 3 could be a useful marker of clinical outcome.

Global trauma scorings systems, such as the Injury Severity score (ISS) and the Revised Trauma score (RTS), are the current standards for assessing the severity of trauma [24,25]. Besides ISS, the Abbreviated Injury scale is the most common and clinically used scoring system, which provides more trauma-related assessment. Similarly, the association between plasma HMGB1 levels and the ISS was also identified in our study.

To our knowledge, blood lactate monitoring is widely used as a primary biomarker of tissue hypoxia in the assessment of the traumatized patient and the critically ill patient admitted to Emergency Department (ED). Several studies have demonstrated lactate measurements, assessed at admission to ED or trauma centre, as being useful in terms of predicting adverse outcome [26-29]. Unfortunately, we did not measure lactate levels in this study. However, we could hypothesize that the combined measurement of HMGB1 and lactate can better predict in-hospital morbidity and mortality in patients with trauma.
There are still some limitations in our study. Firstly, the sample size of blunt chest trauma patients was relatively small in this study. Future studies in a larger patient population might be needed to further validate their clinical association. In addition, sepsis and MODS could be a cause rather than a consequence of higher substrate levels. Furthermore, there were difficulties in obtaining enough blood samples from these patients, which hindered our investigation into the kinetics of plasma HMGB1 levels in long period. Finally, the patients recruited in this study cohort were limited to the Chongqing district. We lack comparison with some biomarkers, such as C-reactive protein, TNF- $\alpha$, procalcitonin.

\section{Conclusion}

In summary, plasma HMGB1 levels were significantly elevated in patients with blunt chest trauma and patients with higher levels of HMGB1 had more severe trauma, as well as a greater number of post-trauma complications incidences. Pathophysiology following blunt chest trauma is complex and influenced by both patient-specific factors and trauma-specific factors. Therefore, one single parameter will not be able to adequately predict the clinical course of chest traumatized patients. However, the study supports that HMGB1 might play an important role in the pathogenesis of sepsis and MODS after blunt chest trauma. Our study demonstrated that daily HMGB1 measurements might be a potential useful tool in the early identification of post-trauma complications. Further studies are needed to determine whether HMGB1 intervention could prevent the development of poor outcome in patients with severe blunt chest trauma.

\section{Abbreviations}

HMGB1: High mobility group box 1; MODS: Multiple organ dysfunction syndrome.

\section{Competing interests}

The authors declare that they have no competing interests.

Authors' contributions

WXW conceived of the study, and participated in its design and coordination and drafted the manuscript. WXW and KK collected blood samples and performed the HMGB1 analysis. KK, ZXJ and XXY managed the hospital stay period of the patient, and collected patient clinical data. LZQ 
was responsible for all data of the study and carried out the final version approval. All authors read and approved the final manuscript.

\section{Acknowledgements}

This work is supported by the Major Program of Chongqing Committee of Science and Technology (CSTC2012jjB10021), and Key Program of the health bureau of Chongqing (ID:2010-1-52, 2011-1-026).

\section{Author details}

${ }^{1}$ Department of Cardiothoracic Surgery, Shanghai Jiao Tong University Affiliated Sixth People's Hospital, NO. 600 Yishan Road, Shanghai 200233, PR China. ${ }^{2}$ Department of Cardiothoracic Surgery, The First Affiliated Hospital, Chongqing Medical University, Chongqing 400016, PR China. ${ }^{3}$ Department of Traumatic Surgery, Chongqing Emergency Medical Center, Chongqing 400016, China.

Received: 1 February 2014 Accepted: 17 July 2014

Published: 2 August 2014

\section{References}

1. Zong ZW, Li N, Cheng TM, Ran XZ, Shen Y, Zhao YF, Guo QS, Zhang LY: Current state and future perspectives of trauma care system in mainland China. Injury 2011, 42:874-878.

2. Billeter A, Turina M, Seifert B, Mica L, Stocker R, Keel M: Early serum procalcitonin interleukin-6, and 24-hour lactate clearance: useful indicators of septic infections in severely traumatized patients. World J Surg 2009, 33:558-566.

3. Biffl WL, Moore EE, Moore FA, Peterson VM: Interleukin- 6 in the injured patient. Marker of injury or mediator of inflammation? Ann Surg 1996, 224:647-664.

4. Angus DC, Yang L, Kong L, Kellum JA, Delude RL, Tracey KJ, Weissfeld L: Circulating high-mobility group box 1 (HMGB1) concentrations are elevated in both uncomplicated pneumonia and pneumonia with severe sepsis. Crit Care Med 2007, 35:1061-1067.

5. Gibot S, Massin F, Cravoisy A, Barraud D, Nace L, Levy B, Bollaert PE: High-mobility group box 1 protein plasma concentrations during septic shock. Intensive Care Med 2007, 33:1347-1353.

6. Sunden-Cullberg J, Norrby-Teglund A, Rouhiainen A, Rauvala H, Herman G, Tracey KJ, Lee ML, Andersson J, Tokics L, Treutiger CJ: Persistent elevation of high mobility group box-1 protein (HMGB1) in patients with severe sepsis and septic shock. Crit Care Med 2005, 33:564-573.

7. Wang H, Yang H, Czura CJ, Sama AE, Tracey KJ: HMGB1 as a late mediator of lethal systemic inflammation. Am J Respir Crit Care Med 2001, 164:1768-1773.

8. Yang H, Ochani M, Li J, Qiang X, Tanovic M, Harris HE, Susarla SM, Ulloa L, Wang H, DiRaimo R, Czura CJ, Wang H, Roth J, Warren HS, Fink MP, Fenton MJ, Andersson U, Tracey KJ: Reversing established sepsis with antagonists of endogenous high-mobility group box 1. Proc Natl Acad Sci U S A 2004, 101:296-301.

9. Kaewlai R, Avery LL, Asrani AV, Novelline RA: Multidetector CT of blunt thoracic trauma. Radiographics 2008, 28:1555-1570.

10. Sauaia A, Moore EE, Johnson JL, Ciesla DJ, Biffl WL, Banerjee A: Validation of postinjury multiple organ failure scores. Shock 2009, 31:438-447.

11. Marshall JC, Cook DJ, Christou NV, Bernard GR, Sprung CL, Sibbald WJ: Multiple organ dysfunction score: a reliable descriptor of a complex clinical outcome. Crit Care Med 1995, 23:1638-1652.

12. Association for the Advancement of Automotive Medicine: The Abbreviated Injury Scale. 2005.

13. Richardson JD, Miller FB, Carrillo EH, Spain DA: Complex thoracic injuries. Surg Clin North Am 1996, 76:725-748.

14. Shorr RM, Crittenden M, Indeck M, Hartunian SL, Rodriguez A: Blunt thoracic trauma. Analysis of 515 patients. Ann Surg 1987, 206:200-205.

15. LoCicero J 3rd, Mattox KL: Epidemiology of chest trauma. Surg Clin North Am 1989, 69:15-19.

16. Calhoon JH, Trinkle JK: Pathophysiology of chest trauma. Chest Surg Clin N Am 1997, 7:199-211.

17. Heroy WW, Eggleston FC: Non penetrating injuries of the chest. N Y State J Med 1951, 51:2515-2520.

18. Peltz ED, Moore EE, Eckels PC, Damle SS, Tsuruta Y, Johnson JL, Sauaia A, Silliman CC, Banerjee A, Abraham E: HMGB1 is markedly elevated within 6 hours of mechanical trauma in humans. Shock 2009, 32:17-22.

19. Levy RM, Mollen KP, Prince JM, Kaczorowski DJ, Vallabhaneni R, Liu S, Tracey K, Lotze MT, Hackam DJ, Fink MP, Vodovotz Y, Billiar TR: Systemic inflammation and remote organ injury following trauma require HMGB1. Am J Physiol Regul Integr Comp Physiol 2007, 293:R1538-1544.

20. Bitto A, Barone M, David A, Polito F, Familiari D, Monaco F, Giardina M, David T, Messina R, Noto A, Di Stefano V, Altavilla D, Bonaiuto A, Minutoli L, Guarini S, Ottani A, Squadrito F, Venuti FS: High mobility group box-1 expression correlates with poor outcome in lung injury patients. Pharmacol Res 2010, 61:116-120.

21. Huang LF, Yao YM, Dong N, Yu Y, He LX, Sheng ZY: Association of high mobility group box-1 protein levels with sepsis and outcome of severely burned patients. Cytokine 2011, 53:29-34.

22. Zhang LT, Yao YM, Yao FH, Huang LF, Dong N, Yu Y, Sheng ZY: Association between high-mobility group box-1 protein release and immune function of dendritic cells in thermal injury. I Interferon Cytokine Res 2010, 30:487-495

23. Huang LF, Yao YM, Zhang LT, Dong N, Yu Y, Sheng ZY: The effect of high-mobility group box 1 protein on activity of regulatory $T$ cells after thermal injury in rats. Shock 2009, 31:322-329.

24. Baker SP, O'Neill B, Haddon W Jr, Long WB: The injury severity score: a method for describing patients with multiple injuries and evaluating emergency care. J Trauma 1974, 14:187-196.

25. Champion HR, Sacco WJ, Carnazzo AJ, Copes W, Fouty WJ: Trauma score. Crit Care Med 1981, 9:672-676.

26. Callaway DW, Shapiro NI, Donnino MW, Baker C, Rosen CL: Serum lactate and base deficit as predictors of mortality in normotensive elderly blunt trauma patients. J Trauma 2009, 66:1040-1044.

27. Shapiro NI, Howell MD, Talmor D, Nathanson LA, Lisbon A, Wolfe RE, Weiss JW: Serum lactate as a predictor of mortality in emergency department patients with infection. Ann Emerg Med 2005, 45:524-528.

28. Kaplan $L$, Kellum JA: Comparison of acid-base models for prediction of hospital mortality after trauma. Shock 2008, 29:662-666.

29. del Portal DA, Shofer F, Mikkelsen ME, Dorsey PJ Jr, Gaieski DF, Goyal M, Synnestvedt M, Weiner MG, Pines JM: Emergency department lactate is associated with mortality in older adults admitted with and without infections. Acad Emerg Med 2010, 17:260-268.

doi:10.1186/s13019-014-0133-5

Cite this article as: Wang et al: High plasma levels of high mobility group box 1 is associated with the risk of sepsis in severe blunt chest trauma patients: a prospective cohort study. Journal of Cardiothoracic Surgery 2014 9:133.

\section{Submit your next manuscript to BioMed Central and take full advantage of:}

- Convenient online submission

- Thorough peer review

- No space constraints or color figure charges

- Immediate publication on acceptance

- Inclusion in PubMed, CAS, Scopus and Google Scholar

- Research which is freely available for redistribution

Submit your manuscript at www.biomedcentral.com/submit
C Biomed Central 